\title{
Law for Decentralized Electricity Systems
}

Lessons from Complexity Theory

\author{
Niko Soininen and Kaisa Huhta
}

\section{Introduction}

Decentralization plays a significant role in democratizing the energy sector. Decentralization describes a process in which there is a shift from centrally planned, financed and operated electricity systems to a more diffuse, decentralized system where the planning, finance and operation of the system is shared between an increasing number of parties. ${ }^{1}$

Decentralization can come in many shapes and scales. This chapter focuses on the electricity sector where electricity production can be decentralized via solar panels, wind farms or diesel generators as well as decentralized network solutions and off-grid solutions such as micro-grids. ${ }^{2}$ In other words, decentralization can occur on many levels of the electricity value chain. Decentralization can also take place within the household of a single consumer or at a larger scale on local and national levels. Overall, decentralization describes a process in which the relative influence and role of large, centralized production and network units decreases in favour of small, decentralized or distributed units of society, such as municipalities, residential blocks, communities and individual citizens and consumers. It also entails a shift from the supply-oriented market model, where centralized producers and large electricity companies are the key players, into a more polycentric system, where the contribution of distributed resources and demand-side actors - consumers - becomes more important. ${ }^{3}$ In other words, decentralization is not only a change on the

1 For further discussion of this issue, see Chapter 1.

2 Subhes C Bhattacharyya and Debajit Palit, 'Mini-grid based off-grid electrification to enhance electricity access in developing countries: What policies may be required?' (2016) 94 Energy Policy 166-178; Peter Alstone, Dimitry Gershenson and Daniel M Kammen, 'Decentralized energy systems for clean electricity access' (2015) 5 Nature Climate Change 305-314, 307.

3 Breffní Lennon and others, 'Citizen or consumer? Reconsidering energy citizenship' (2020) 22 Journal of Environmental Policy \& Planning (2), 184-197; Patrick Devine-Wright, 'Energy citizenship: Psychological aspects of evolution in sustainable energy technologies', in Joseph Murphy (ed), Governing Technology for Sustainability (Routledge 2007) 240; Rehman Zafar and 
structural level of the electricity sector, but also a transformation on an individual level due to the increasing opportunities afforded to consumers. ${ }^{4}$

Decentralization can bring benefits but it can also complexify electricity systems and increase risk. In the context of sustainable energy democracy, its benefits are twofold. The first concerns the measures needed to address climate change. The process of decreasing dependence on fossil fuels by increasing the share of renewable energy sources requires, in particular, that electricity systems become better equipped to address the intermittency associated with renewable energy production. Decentralization of the electricity sector is key both to increasing the flexibility of the electricity system and gaining financing from individuals - not just states or businesses - to facilitate the energy transition. ${ }^{5}$ In fact, it is generally thought that the transition to a renewable-based electricity system cannot take place to a sufficient extent without decentralization. ${ }^{6}$

In the context of sustainable energy democracy, the second benefit of decentralization concerns the mitigation of energy poverty and allowing access to affordable and clean energy. ${ }^{7}$ Decentralization contributes to these objectives in several ways. Renewable energy sources, such as sunlight or wind, are more equally dispersed around the globe than fossil fuels and, therefore,

others, 'Prosumer based energy management and sharing in smart grid' (2018) 82 Renewable and Sustainable Energy Reviews 1675-1684; Sharon B Jacobs, 'The Energy Prosumer' (2016) 43 Ecology Law Quarterly (3), 519-580; Lea Diestelmeier, 'Changing power: Shifting the role of electricity consumers with blockchain technology - Policy implications for EU electricity law' (2019) 128 Energy Policy 189-196; Kacper Szulecki, 'Conceptualizing energy democracy' (2018) 27 Environmental Politics (1) 21-41, 22 and 31; Saskia Lavrijssen, 'Power to the Energy Consumers' (2017) 26 European Energy and Environmental Law Review 6, 172-187, 173; Maciej M Sokolowski, 'Renewable Energy Communities in the Law of the EU, Australia, and New Zealand' (2019) 28 European Energy and Environmental Law Review (2), 34-46; Maciej M Sokolowski, 'European Law on the Energy Communities: a Long Way to a Direct Legal Framework' (2016) 27 European Energy and Environmental Law Review (2) 60-70.

4 Christoph Burger and others, Decentralised Energy: A Global Game Changer (Ubiquity Press 2020) 2. See also Chapter 5 .

5 ibid 22.

6 Mudathir Funsho Akorede, Hashim Hizam and Edris Pouresmaeil, 'Distributed energy resources and benefits to the environment' (2010) 14 Renewable and Sustainable Energy Reviews 724-734.

7 Also included as the 7 th Sustainable Development Goal. For further discussion, see Andreas Goldthau, 'Rethinking the governance of energy infrastructure: Scale, decentralization and polycentrism' (2014) Energy Research \& Social Science 1, 134-140; Alstone, Gershenson and Kammen (n 2) 305-314; Patrick Nussbaumer, Morgan Bazilian and Vijay Modi, 'Measuring energy poverty: Focusing on what matters' (2012) 16 Renewable and Sustainable Energy Reviews 1, 231-243. 
they are also commonly available in places that do not have an abundance of other energy resources. Due to the availability of renewable energy sources in many areas, decentralized generation and supply do not necessarily have to be connected to a centralized electricity system, which makes them the best option for supplying electricity to peripheral areas with no access to centralized systems. Consequently, people and local communities across the globe can produce their own clean energy and reap the economic benefits of this production. ${ }^{8}$

While decentralization contributes to these objectives, it also increases the number of variables in the electricity sector by increasing the influence and number of smaller, active parties within it. ${ }^{9}$ This complicates both the electricity system itself and the efforts being made to govern it through legal means. ${ }^{10}$ If this complexity is not adequately acknowledged and addressed, it may have consequences that hinder rather than facilitate energy democracy. Moreover, increasing complexity due to decentralization may threaten energy security as more actors influence the electricity system and there is less centralized control over it.

In the electricity sector, legal frameworks have traditionally been designed to address a relatively stable centralized system, where large producers and network operators have the financial, professional and operational capacity to fulfil the regulatory requirements placed upon them. Decentralization challenges this traditional legal approach, because the electricity sector is increasingly operated by a more diverse group of actors who produce electricity when doing so serves their interests rather than when it serves the interests of the electricity system as a whole. Therefore, there is a need to evaluate whether and how legal systems can address this increasing complexity.

This chapter approaches this issue by applying complexity theory to decentralized electricity systems and sets out two main arguments. First, it argues that complexity theory provides a valuable perspective for understanding how decentralized electricity systems function. Second, it argues that the theory can be used to critically evaluate whether energy law is equipped to address the complexity that increases as decentralization advances in electricity systems.

Complexity theory is produced by complexity science, which is an interdisciplinary field of research studying complex systems in which large networks

8 Alstone, Gershenson and Kammen (n 2) 307; Yannick Glemarec, 'Financing off-grid sustainable energy access for the poor' (2012) 47 Energy Policy 87-93.

9 Edward J Oughton and others, 'Infrastructure as a Complex Adaptive System' (2018) Complexity $1-11,4-5$. ibid. 
of components and/or agents collectively produce emergent, surprising dynamics. ${ }^{11}$ While still in its infancy as a scientific discipline, the goal of complexity science is to understand why and how complex systems evolve. In legal scholarship, complexity theory has emerged as a criticism of rigid legal frameworks that assume state-centred, predictable and stable regulation of complex systems. ${ }^{12}$ Complexity theory has been used to evaluate the ability of legal systems to govern complexity, change and uncertainty. ${ }^{13}$ In environmental law, for instance, complexity theory has been used to argue that environmental law fails to achieve its objectives because it does not take sufficient account of the fact that ecosystems are constantly changing and fundamentally unpredictable. ${ }^{14}$

Complexity theory is used in two ways in this chapter. In making the first argument, the theory provides an analytical framework to explain the object of regulation, i.e. decentralized electricity systems. In making the second argument, it provides a methodological lens through which to identify the key legal design elements needed for governing a complex system, such as a decentralized electricity system, and to evaluate whether existing laws can adequately withstand and respond to changing dynamics in such a complex system. In other words, complexity theory is first used to describe how electricity systems operate. The chapter then assesses what this means for effectively governing such complex systems through law.

To demonstrate the application of complexity theory to decentralized electricity systems, this chapter uses the EU as a case study. There are several reasons for this focus on the EU. Decentralization in the EU is topical in the context of its climate goals, which rely on the achievement of ambitious renewable energy targets and a significant increase in decentralized solutions. ${ }^{15}$ The EU has also recently adopted a new legal framework to facilitate the increase of decentralized renewable electricity. ${ }^{16}$ Finally, the EU is an illustrative regional

\footnotetext{
11 Melanie Mitchell, Complexity: A Guided Tour (oup 20o9) 3 and 12.

12 Robin Kundis Craig andJB Ruhl, 'Designing Administrative Law for Adaptive Management' (2014) 67 Vanderbilt Law Review (1) $1-87$; Barbara A Cosens and others, 'The role of law in adaptive governance' (2017) 22 Ecology and Society (1) 1-12.

13 ibid.

14 ibid.

15 Kati Kulovesi and Sebastian Oberthür, 'Assessing the EU's 203o Climate and Energy Policy Framework: Incremental Change towards Radical Transformation' (2020) 29 Review of European, Comparative and International Environmental Law (2) 151-166.

16 J Lowitzsch, C E Hoicka and F J van Tulder, 'Renewable energy communities under the 2019 European Clean Energy Package - Governance model for the energy clusters of the future?' (2020) 122 Renewable and Sustainable Energy Reviews 1-13.
} 
example of how decentralization can be governed through transnational legal solutions. These factors make it an ideal case study for the purposes of this chapter.

The chapter is structured as follows. After the introduction, section 2 focuses on complexity theory and its implications to explain how decentralized electricity systems function. Section 2 develops the first argument by illustrating how electricity markets reflect complex system dynamics. Section 3 turns to the second argument. It identifies the key criteria that can be used to evaluate legal instruments that govern complex systems and applies them to the EU Clean Energy for All Europeans package (CEP) to assess whether it is equipped to address the complexity of decentralized electricity systems. Conclusions are provided in section 4 .

Complex systems have unique properties and dynamics that are described and explained by complexity theory, which is an explanatory theoretical framework that seeks to describe and explain what makes systems complex and why. In essence it suggests that the properties and dynamics of complex systems are not reducible to their components or agents and that they consequently produce dynamics that are surprising and extremely hard to predict. ${ }^{17}$ This section uses complexity theory to explain the properties and dynamics of decentralized electricity systems and the challenges that emerge in governing them through law. The main properties and dynamics can be divided into agent, network and system levels, all of which are relevant in order to understand and explain the complexity of decentralized electricity systems. ${ }^{18}$ These three levels interact in numerous ways. ${ }^{19}$

Agent level properties refer to the adaptive behaviour of individuals, households and firms. Agents respond and adapt to different supply and demand side drivers, such as price of service and new technologies. ${ }^{20}$ In decentralized electricity systems, changes in agent level dynamics are key to understanding the complexity of decentralization. In traditional, centralized electricity markets, the division of roles between producers, suppliers and customers is relatively stable and rigid. As analysed in more detail in Chapter 6, centralized markets

\footnotetext{
$17 \quad$ Mitchell (n 11) 3 and 12.

18 Oughton and others (n 9) 4-5.

19 ibid 5 .

$20 \quad$ ibid 4.
} 
rely on a limited number of large producers that generate electricity for a large number of customers, whose passive role is to consume the produced electricity. ${ }^{21}$ The network operators that supply the electricity are typically equally centralized. In addition to a limited number of stable and large suppliers, the demand side has also traditionally been rigid and inflexible. Industrial and particularly household customers have not switched suppliers very actively and have had relatively predictable patterns of demand, which are dependent on the time of year and day, weather and economic conditions, for example. ${ }^{22}$

In stark contrast, a decentralized system builds on the diverse and intertwined roles of producer and consumer agents. ${ }^{23}$ In a decentralized system, more consumers take up roles as producers as well as consumers of electricity (prosumer). ${ }^{24}$ Consumers may also participate in community energy projects, which allow individuals to finance, own, manage and use the electricity they produce in their communities. ${ }^{25}$ In essence, a decentralized system allows individuals to have more influence over their energy choices, as discussed in Chapter $1 .{ }^{26}$

The independence of these consumer agents from the centralized system varies, however, as is discussed further in Chapter 6. Some household consumers can be entirely independent of a centralized system by producing their own electricity. They might even supply some of that electricity to the surrounding community through a micro-grid. ${ }^{27}$ However, prosumers are rarely entirely self-sufficient. They may rely on the centralized system to supply them during low availability of intermittent renewable generation or they may be connected to the central grid to feed their excess generation into the centralized electricity system..$^{28}$ To a large extent, both systems co-exist in parallel and interact with one another. ${ }^{29}$ Because of these variables in agent-level choices and the variance in their connection to the centralized system, the general output of a decentralized electricity system cannot be predicted with the same level of certainty as is the case in respect of a centralized system.

\footnotetext{
21 Kaisa Huhta, 'Unleashing Consumer Potential in the Energy Transition: A Reflection of the Transforming Role of the EU Consumer' (2019) 3 Oil, Gas \& Energy Law 1-10.

22 ibid.

23 Burger and others (n 4) 22.

24 For further information, see Chapter 6.

25 For further information, see Chapter 6.

26 For further information, see Chapter 1.

27 Alstone, Gershenson and Kammen (n 2) 307.

28 Burger and others (n 4) 22.

29 ibid 1.
} 
Against this background it seems that the decentralization of the electricity sector is mostly a shift in agent level choices. Where decentralization occurs, consumers' adaptive capacity significantly increases as they have the opportunity to assume the role of both consumer and producer more freely. With this freedom comes the possibility to experiment with new roles and to learn which roles produce the best outcomes to suit agent preferences, i.e. the subjective aims of the consumer making choices. The interconnectedness of consumer agents and the mixed role of these agent has important implications at the level of networks and systems.

Networks, to which the agents contribute, reflect continuous dynamic change in which the infrastructure in question goes through a constant process of expansion and modification: it co-evolves with technological innovation and societal development. ${ }^{30}$ Networks, as they are understood in complexity theory, should be distinguished from electricity transmission and distribution networks themselves. In the light of complexity theory, the entire electricity system can be considered a network of mutually interlinked and interactive elements comprising not only physical components but also its agents' social and economic choices. ${ }^{31}$ The network level has several characteristics that have important implications for understanding decentralized electricity systems.

Networks undergo dynamic change, which means that they never reach equilibrium. Infrastructure networks are open entities in the sense that there is a constant inward and outward flow of goods, services and capital, and they lack fixed boundaries between the system and other nested systems. ${ }^{32}$ Networks also reflect irreversibility in the sense that infrastructure decisions are path-dependant. They are constructed and operated within the limitations of existing infrastructures, which also means that decisions made today will have a lasting influence on the future functioning of the system. ${ }^{33}$ For instance, electricity infrastructure investment, which has a lifespan of about 50 years, creates long-term path-dependencies as to what can and cannot be done within the system. While network operators have an obligation to develop these infrastructures, they do so within the limitations of the path-dependencies created by previous investment choices. Decentralized electricity systems are inherently dynamic particularly in the context of the energy transition, which describes a fundamental change that has occurred for

\footnotetext{
$30 \quad$ Oughton and others (n 9) 4-5.

31 ibid.

32 Oughton and others (n 9) 4.

33 ibid.
} 
decades and will continue for several decades to come. ${ }^{34}$ In fact, it is unlikely that the energy sector will reach a point at which the transition can be declared entirely achieved. ${ }^{35}$ In the shorter term, the dynamic nature of decentralized systems is likely to be reflected in rapidly developing technologies and innovation that allow the development of new business models and ways of facilitating the low-carbon transition, as well as new roles for consumers. Taken together, the agent-level and network level properties described here lead to system level dynamics, as described below.

Finally, at the aggregate system level, complex systems have six key characteristics that need to be carefully considered in regulating such systems: (1) emergence, (2) indeterminacy, (3) adaptation, (4) non-linearity, (5) self-organisation, and (6) nestedness. ${ }^{36}$

Emergence is typically explained as the whole being more than the sum of the parts'37. In other words, emergence means that the system produces patterns or regularities that cannot be inferred from how the components or agents within the system operate in isolation from one another. Emergence brings about fundamental indeterminacy about how the system will operate in the future. The diversity in the roles and responsibilities of consumers and their potential linkages to the centralized system makes a decentralized electricity system highly emergent. The adaptive behaviour of a single consumer in a centralized system is unlikely to cause extensive patterns or regularities that could alter the overall electricity system. However, a decentralized system is characterized by an increasing number of active individuals that act based on different drivers, motivators and economic inputs. Some may have invested in a solar panel to gain access to electricity in an area otherwise disconnected from the centralized grid. Others may have become involved with renewable energy communities because of an increasing awareness of the carbon footprint of their household energy consumption. Some may simply have found decentralized generation options the cheapest way to meet their energy needs. ${ }^{38}$

\footnotetext{
34 ibid 4.

35 Geert Verbong and Derk Loorbach, Governing the Energy Transition: Reality, Illusion or Necessity? (Routledge Studies in Sustainability Transitions 2012) 6-14.

36 ibid 5; Barbara Cosens and others, 'Designing Law to Enable Adaptive Governance of Modern Wicked Problems' (2020) 73(6) Vanderbilt Law Review 1687.

37 Fritjof Capra and Pier Luigi Luisi, The Systems View of Life: A Unifying Vision (Cambridge University Press 2014) 63-67. On the development of complexity theory, see Ludwig von Bertalanffy, General System Theory: Foundations, Developments, Applications (George Braziller, 1968); and Ralph H Abraham, 'The Genesis of Complexity' (2011) 67 World Futures (4-5) 380-394. 
If consumers start shifting to decentralized generation in large numbers for economic, climate or other reasons, the system will likely witness emerging dynamics that are somewhat different from those of a centralized system. To summarize, decentralization increases the agent-level variables, which in turn can affect the network and system level dynamics significantly. Because of this high level of variation, predicting the development of decentralized systems accurately becomes extremely difficult, if not altogether impossible. ${ }^{39}$

Adaptation refers to agents' capacity to learn and modify their behaviour in the light of how other agents in the system operate. ${ }^{40}$ In a decentralized system, the adaptive capacity of consumer agents can affect the dynamics on a system level if individual consumers' choices encourage or discourage large numbers of other consumers to follow their example. In fact, a rather small shift in the initial conditions can have disproportionate, non-linear outcomes. The mixed role of consumers as both the consumer and the producer of electricity also changes the system from being unidirectional to being multidirectional. ${ }^{41} \mathrm{In}$ other words, the consumer changes from a passive recipient of electricity to an active market participant. ${ }^{42}$ This increases the likelihood of non-linear system dynamics as the agents, i.e. consumers, operating within the system have more options to respond to electricity prices and technological developments, and consequently new network and system level dynamics are likely to emerge. ${ }^{43}$ For example, smart meters have allowed consumers to enter into dynamic price contracts, where the price of electricity changes on an hourly basis. ${ }^{44}$ Consumers can, therefore, cut their electricity bills by shifting and reducing demand during peak hours when prices are high and, through such responses, change the outcomes of the electricity system as a whole. ${ }^{45}$

The increasing diversity of actors' roles in a decentralized system also affects the self-organization of the market. ${ }^{46}$ Irrespective of the role that centralized actors continue to play in the electricity market, individuals' increasing freedom of choice means that there is no single legal or organisational structure that can comprehensively control the development of a decentralized

39 Merla Kubli and Silvia Ulli-Beer, 'Decentralisation dynamics in energy systems: A generic simulation of network effects' (2016) 13 Energy Research \& Social Science 71-83, 71.

40 John H Holland, Complexity: A Very Short Introduction (OuP 2014) 11.

$41 \quad$ Kubli and Ulli-Beer (39) 71.

42 Huhta (n 21) 1-10.

43 Verbong and Loorbach (n 35) 9.

44 Kaisa Huhta, 'Smartening up while keeping safe? Advances in smart metering and data protection under EU law' (2019) 38 Journal of Energy \& Natural Resources Law (1) 5-22.

45 Huhta (n 21) 1-10.

46 Holland (n 40) 5 . 
electricity system. Although elements of the electricity system, such as centralized transmission and distribution networks, are controlled by network system operators, the broader electricity system is a living entity that is controlled by all and none of the actors involved in the system.

Finally, complex systems are often characterized as nested on various hierarchical levels. ${ }^{47}$ In decentralized electricity systems, this is represented most clearly in the way the energy sector is governed on global, regional, national and local levels. Each level operates as a complex system, but the levels also affect one another. Global changes in the production and trade of components needed for decentralized electricity systems necessarily affect the choices that can be made on regional or local levels. Similarly, changes in demand at the local level of decentralization affect the dynamics on a global level. Moreover, complex systems do not operate in isolation from one another. They are connected to myriad other systems, such as the economy, biosphere, society and most importantly, from the point of view of this chapter, law. ${ }^{48}$

What, then, are the implications of complexity theory for law in general and regulating decentralized electricity systems in particular? In short, the theory suggests that complex systems are dynamic in the sense that they cannot be entirely or exhaustively controlled by a central regulator on a state level or even on a regional level, such as the EU. ${ }^{49}$ Certain elements of the electricity system, such as the physical safety and load-balancing are controlled by network system operators. However, the electricity system as a whole, comprising everything from the choices of an individual active consumer to broader market dynamics, cannot be exhaustively governed by a regulator. A second major implication of the theory is that the operation of such systems cannot be entirely modelled or predicted scientifically ex ante for reasons of indeterminacy, non-linearity and extreme sensitivity to changes in system components. ${ }^{50}$ Therefore, the complexity of decentralized electricity systems has important implications for regulating decentralization in a way that facilitates rather than hinders energy democracy, as demonstrated in the following section. The next section uses complexity theory to identify the key legal design

47 ibid 4; B Walker and others, 'Resilience, adaptability and transformability in socialecological systems' (2004) 9 Ecology and Society (2) 4, available at https://www.ecologyandsociety.org/voly/iss2/art5/ accessed 21 September 2020.

48 Capra and Luisi (n 37).

49 On the controllability of complex systems in general, see G P J Dijkema, Z Lukszo and M P C Weijnen, 'Chapter 1 Introduction' in Koen H Dam and others (eds), Agent-Based Modelling of Socio-Technical Systems (Springer 2013) 1-10, 4. Oughton and others (n 9) 5 . 
elements needed to govern a complex system such as a decentralized electricity system and, by using the EU as a case study, to assess whether existing laws can adequately withstand and respond to the characteristics of such a complex system.

\section{Evaluating the EU Legal Framework for Decentralized Electricity through Complexity Theory}

\subsection{Evaluation Criteria for Laws Regulating Complex Systems}

Complexity theory has been extensively discussed in the context of environmental legal scholarship since at least the 199os. ${ }^{51}$ The core argument in this discussion is that environmental law fails to achieve its objectives because it does not take sufficiently into account the fact that ecosystems are complex in other words that they are constantly changing and fundamentally unpredictable. Classical environmental law has been criticized on the grounds that it is largely based on the assumption that central governments have the power and capacity to exclusively control the inputs and outputs of these systems; that the systems are stable and predictable; and that governmental control can be exerted through clear, predictable and unchanging legal rules. ${ }^{52}$ In reality the systems are complex and characterized by emergence, indeterminacy, adaptation, non-linearity, self-organization and nestedness and, consequently, classical doctrines of legal regulation do not sit comfortably with the regulatory reality on the ground. Based on the analysis set out in section 2 above, the same can be said about the regulation of decentralized electricity systems.

After laying bare the criticism of conventional state-centred command and control regulation, much of the legal scholarship inspired by complexity theory has been about establishing functional criteria for designing and evaluating laws that seek to regulate complex systems. ${ }^{53} \mathrm{~A}$ key question in evaluating such laws is to determine how well the legal framework can deal with change

$5^{1}$ An early classic is J B Ruhl, 'Thinking of Environmental Law as a Complex Adaptive System: How to Clean Up the Environment by Making a Mess of Environmental Law' (1997) 34 Houston Law Review 101, 933-1102.

52 Ruhl (n 51) 933-1102; J B Ruhl, 'General Design Principles for Resilience and Adaptive Capacity in Legal Systems - With Applications to Climate Change Adaptation' (2010) 89 North Carolina Law Review (5) 1373-1401; Cosens and others (n 12) 1-12; Robin Kundis Craig and others, 'Balancing stability and flexibility in adaptive governance: an analysis of tools available in U.S. environmental law' (2017) 22 Ecology and Society (2) 1-15; Cosens and others (n 36$)$.

Ruhl (n 52) 1373-1401; Craig and Ruhl (n 12) 1-87; Cosens (n 12) 1-12. 
and uncertainty in the regulated system. ${ }^{54}$ This chapter identifies three main criteria for regulating complex systems.

The first criterion is that legal frameworks regulating complex systems should be based on decentralized, market-based and/or local action geared towards democratically agreed and legally binding goals. The justification for this criterion is that market actors and citizens are in a far more agile position to adjust their own behaviour regarding the set goals as new dynamics emerge in complex systems than the government is in changing specific legal requirements. ${ }^{55}$ Government oversight should also be left to the level closest to system management. ${ }^{56}$ While market-based approaches to energy democracy are also open to criticism, ${ }^{57}$ they are favoured in the light of legal theories facilitating the regulation of complexity.

Second, to mitigate societally unwanted market and/or local dynamics, law needs to provide institutional, procedural and substantive safeguards. These include levelling the playing field for market actors and citizens, but also adopting legal safeguards to prepare the system for shocks and surprising system dynamics and to be capable of learning from them. ${ }^{58}$

Third, the legal framework should establish a monitoring programme to keep track of the system dynamics and sketch new scenarios and pathways to achieve binding goals. These monitoring and scenario frameworks need to be connected with an iterative evaluation and changing of goals, institutional structures, processes and substantive policy instruments designed to implement the goals. They shall cater for evolving - and surprising - system dynamics. ${ }^{59}$

The next section uses the EU legal framework for decentralized electricity as an example that illustrates whether these three sets of criteria are met and whether EU energy law can adequately withstand and respond to changing

54 ibid.

$55 \quad$ Ruhl (n 52) 1373-1401; Cosens and others (n 36 ).

56 Michael C Dorf and Charles F Sabel, 'A Constitution of Democratic Experimentalism' (1998) 98 Columbia Law Review 267-473; Ruhl (n 52) 1373-1401; Craig and others (n 52) 1-15; Niko Soininen and Froukje Maria Platjouw, 'Resilience and Adaptive Capacity of Aquatic Environmental Law in the EU', in D Langlet and R Rayfuse (eds), The Ecosystem Approach in Ocean Planning and Governance (Brill 2019).

57 See Chapter 2.

$5^{8}$ Cosens (n 12) 1-12; Craig and others (n 52) 1-15; Robin Kundis Craig and others, 'Chapter 11: Stability and Flexibility in the Emergence of Adaptive Water Governance' in Barbara Cosens and Lance Gunderson (eds) Practical Panarchy for Adaptive Water Governance: Linking Law to Social-Ecological Resilience (Springer Publications 2018) 167182; Cosens and others ( $n_{36}$ ).

Cosens and others $\left(\mathrm{n}_{36} 6\right)$. 
dynamics in such a complex system. The analysis focuses on the CEP, which is the fourth and most recent legislative package for energy. ${ }^{60}$ It comprises several amendments of existing legal instruments as well as entirely new legal instruments. ${ }^{61}$ One of its key changes, as compared to the previous legal framework, is the new set of rules on decentralized electricity. ${ }^{62}$

\subsection{Facilitating Market-Based Bottom-Up Approaches}

The CEP is premised on the idea that consumers are incentivized to generate their own electricity by falling technology prices and the ability to sell excess electricity back to the grid, thereby reducing their overall energy costs. However, objectives established at treaty level are the starting point for analysis of the CEP. In other words, while this chapter analyses the CEP, it is first necessary to focus on the constitutional foundations on which the package rests. The CEP is based on the competences and legal bases enshrined in primary law, most importantly the Treaty on the Functioning of the European Union (TFEU) and the Treaty on European Union (TEU). ${ }^{63}$ The objectives of EU energy law are established in Article $194 \mathrm{TFEU}$, which states that the EU aims

6o Communication from the Commission to the European Parliament, the Council, the European Economic and Social Committee, the Committee of the Regions and the European Investment Bank, Clean Energy For All Europeans, сом(2016) 860 final; Regulation (EU) 2019/943 of the European Parliament and of the Council of 5 June 2019 on the internal market for electricity [2019] OJ L158/54 (hereinafter the 'Electricity Regulation'); Directive (EU) 2019/944 of the European Parliament and of the Council of 5 June 2019 on common rules for the internal market for electricity and amending Directive 2012/27/EU [2019] OJ L158/125 (hereinafter the 'Electricity Directive'); Regulation (EU) 2019/941 of the European Parliament and of the Council of 5 June 2019 on risk-preparedness in the electricity sector and repealing Directive 2005/89/EC [2019] OJ L158/1 (hereinafter the 'Risk-Preparedness Regulation'); Regulation (EU) 2018/1999 of the European Parliament and of the Council of 11 December 2018 on the Governance of the Energy Union and Climate Action, amending Regulations (EC) No 663/2009 and (EC) No 715/2009 of the European Parliament and of the Council, Directives 94/22/EC, 98/ 70/EC, 2009/31/EC, 2009/73/EC, 2010/31/EU, 2012/27/EU and 2013/30/EU of the European Parliament and of the Council, Council Directives 2009/119/EC and (EU) 2015/652 and repealing Regulation (EU) No 525/2013 of the European Parliament and of the Council [2018] OJ L328/1 (hereinafter the 'Energy Union Governance Regulation'); and Directive (EU) 2018/2001 of the European Parliament and of the Council of 11 December 2018 on the promotion of the use of energy from renewable sources [2018] OJ L328/82 (hereinafter 'REDII').

61 ibid.

62 See, for instance, chapter III of the Electricity Directive on consumer empowerment and protection.

63 Consolidated Version of the Treaty on the Functioning of the European Union, oJ $\mathrm{C}_{326}$ / 47; Consolidated Version of the Treaty on European Union, oJ $\mathrm{C}_{326 / 13}$. 
to ensure the functioning of the energy market and security of energy supply as well as promote energy efficiency, energy saving, the development of new and renewable forms of energy and the interconnection of energy networks. Any legal action in the energy sector must always be grounded on these legal objectives. ${ }^{64}$ While decentralization is not explicitly mentioned in Article 194 TFEU, the legal instruments of the CEP adopted on the basis of it proceed from the assumption that decentralization facilitates these general objectives by increasing the utilization of local energy sources and local security of energy supply, thus achieving shorter transport distances and reduced energy transmission losses. ${ }^{65}$ The CEP's legal instruments also recognize the overall benefits of decentralization: decarbonization and guaranteeing affordable access to all consumers. ${ }^{66}$ The CEP emphasizes the need to put consumers at the heart of the energy transition and to utilize their potential to achieve the flexibility necessary to adapt the electricity system to variable and distributed renewable electricity generation. ${ }^{67}$ For example, the CEP gives consumers the right to dynamic price and aggregation contracts, which enable them to increase the flexibility of the demand side. ${ }^{68}$

The roots of the bottom-up approaches taken under EU law are grounded on a constitutional level. All competences that have not been conferred upon the EU through the treaties remain with the Member States. ${ }^{69}$ This means that while the EU may regulate decentralized electricity, it can only do so within its explicit competences, which are governed by the principles of subsidiarity and proportionality. ${ }^{70}$ In relation to decentralization and the democratization

64 TEU art 5(2); Paul Craig and Gráinne de Búrca, EU Law: Text, Cases, and Materials (6th edn oup 2015) 73-104; Armin von Bogdandy, 'Founding Principles', in Armin von Bogdandy and Jürge Bast (eds), Principles of European Constitutional Law (revised 2nd edn, Hart Publishing 2011) 9-54, 3-37.

65 REDII recital 65.

66 Electricity Directive recital 6 and arts 1 and 3.

67 Electricity Directive recital 10 and arts 1 and 3. In legal literature, see Lavrijssen (n 3) 172187,173 .

68 Electricity Directive arts 11 and 13.

69 TEU art 5(2). See also Bram Delvaux, EU Law and the Development of a Sustainable, Competitive and Secure Energy Policy: Opportunities and Shortcomings (Intersentia 2013) 107-112; Leigh Hancher and Sally Janssen, 'Shared Competences and Multi-Faceted Concepts - European Legal Framework for Security of Supply', in Barry Barton and others (eds), Energy Security: Managing Risk in a Dynamic Legal and Regulatory Environment (OUP 2004) 85-119.

70 Andrea Biondi, 'Subsidiarity in the Courtroom', in Andrea Biondi, Piet Eeckhout and Stefanie Ripley (eds), EU Law after Lisbon (oup 2012) 213-227; Armin von Bogdandy, 'Founding Principles', in von Bogdandy and Bast (n 64) 9-54, 35-36; Wolf Sauter, Proportionality in EU Law: A Balancing Act?' (2012) 15 Cambridge Yearbook of European 
of the energy sector, the principle of subsidiarity is the more relevant of the two. In accordance with this principle, the EU can only act if and in so far as the objectives of the proposed action cannot be sufficiently achieved by the Member States, either at state or regional and local level, but can rather, by reason of the scale or effects of the proposed action, be better achieved at EU level. ${ }^{71}$ In other words, this principle requires that any legislative action should be taken as close as possible to the people that are affected. Although the principle of subsidiarity has never been successfully invoked before the EU courts, it may be seen as a facilitator of energy democracy by encouraging bottomup approaches and decentralized decision-making in the light of complexity theory. ${ }^{72}$ From the complexity theory perspective, the subsidiarity principle is therefore a manifestation of a legal structure that facilitates action at the lowest possible governance level. It does not, however, follow from this that the EU should entirely abstain from regulating decentralization. As further explained in section 3.3 below, some level of centralized legal governance is needed to address potential unwanted market-based dynamics.

In addition to favouring bottom-up approaches, EU law is fundamentally based on internal market logic in pursuing its objectives. ${ }^{73}$ The nature of this logic is specifically laid down in the EU treaties and entails the internal market working in favour of objectives such as sustainable development, achieving a highly competitive social market economy, full employment and social progress and a high level of protection and improvement of the quality of the environment. ${ }^{74}$ This provision is a manifestation of the underlying assumption that the market-based approach followed in the context of EU law is an appropriate instrument by which to achieve diverse and complex objectives such as full employment or high environmental quality standards - or, in the case of energy law, energy security and a high share of renewable energy sources, for

Legal Studies 2, 439-466; Ulrich Everling, 'The European Union as a Federal Association of States and Citizens', in von Bogdandy and Bast (n 64) 701-734; Tor-Inge Harbo, The Function of Proportionality Analysis in European Law (Brill Nijhoff 2015); Nigel Foster, Foster on EU Law (OUP 2015) 78, 86-91.

71 TEU art 5(3); Craig and de Búrca (n 64) 95-101.

72 Biondi (n 7o) 213-227; Foster (70) 86-89; Bogdandy, 'Founding Principles', in von Bogdandy and Bast (n 64) 9-54, 35-37.

73 Catherine Barnard and Steve Peers (eds), European Union Law (oup 2014) 1-2; Friedl Weiss and Clemens Kaupa, European Union Internal Market Law (Cambridge University Press 2014) 1-3.

74 TEU art 3(3); Stephen Weatherill, The Internal Market as a Legal Concept (OUP 2017) 3348; Wolf Sauter, 'Public Services and the Internal Market: Building Blocks or Persistent Irritant?' (2015) 21 European Law Journal 6, 738-757, 743. 
example. ${ }^{75}$ While states are still the hubs of legal power in the energy sector, the underlying expectation that informs EU law is that the market, rather than states, will increasingly self-regulate and work in favour of the objectives set at EU level. ${ }^{76}$

Despite binding goals and the facilitation of bottom-up market mechanisms, the key challenge in the CEP, from a complexity perspective, is the plurality of its goals. ${ }^{77}$ The package aims to achieve carbon neutrality in the energy system while protecting consumers and increasing their influence in the system. At the same time, however, while these transformative changes take place, it seeks to ensure that other valuable objectives of Article 194 TFEU, such as energy security, are protected. For instance, the Electricity Directive aims to maintain 'a high degree of security of supply' while facilitating 'a smooth transition towards a low-carbon energy system'. ${ }^{78}$ In the light of complexity theory and the criteria developed above, the first goal is about disrupting the current carbon-dependant and non-democratic system with the CEP, and the second about preserving objectives such as energy security. The disruptive elements of the CEP, such as the increased role for prosumer agents, can have a destabilizing effect on maintaining the equilibrium between supply and demand. Because of the plurality of goals involved, the CEP is likely to produce both unintended positive and negative effects on decentralized electricity systems, some of which may foster carbon neutrality, democracy or energy security, or none of them. Moreover, legal systems are complex in their own right, which means that CEP's indirect effects on the electricity systems are hard - if not impossible - to predict. ${ }^{79}$

\subsection{Legal Mechanisms for Checking Unwanted Market Dynamics}

The second evaluation criterion focuses on the institutional, procedural and substantive safeguards for checking unwanted market dynamics stemming from decentralization. This section focuses on two of these dynamics, i.e.

75 Weiss and Kaupa (n 73) 2; Bruno de Witte, 'A Competence to Protect: The Pursuit of nonmarket aims through internal market legislation', in Phil Syrpis (ed), The Judiciary, the Legislature and the EU Internal Market (Cambridge University Press 2012) 49-62.

76 Kaisa Huhta, 'Trust in the invisible hand? The roles of the State and the markets in EU energy law' (2020) 13 Journal of World Energy Law \& Business (1) 1-11.

77 Kaisa Huhta, Anchoring the Energy Transition with Legal Certainty in EU Law' (2020) Maastricht Journal of European and Comparative Law 1-20.

78 Electricity Directive art 1.

79 J B Ruhl and Daniel Martin Katz, 'Measuring, Monitoring, and Managing Legal Complexity' (2015) 101 Iowa Law Review 229-231; J B Ruhl, Daniel Martin Katz and Michael J Bommarito II, 'Harnessing Legal Complexity' (2017) 355 Science (6332) 1377-1378. 
whether decentralization would (1) create injustices for individual consumers; or (2) lead to uncertainty and risk related to energy security. From an energy democracy perspective, and with an eye to the first unwanted system dynamic, this means that the legal framework needs to maintain a level playing field for market actors and protect against inequalities that may arise in decentralized electricity markets. From an energy security perspective, and with an eye to the second dynamic, the legal framework requires tools for managing expected and unexpected consequences of the transitioning electricity sector with an increasing share of variable power generation. These two unwanted dynamics and their regulatory remedies are discussed separately below.

The first market dynamic involves providing a level playing field for decentralized market actors. The CEP includes procedural provisions on how active consumers and energy communities can influence decisions made in the electricity sector. For example, Member States are obliged to ensure that the public is given early and effective opportunities to participate in the preparation of the draft integrated national energy and climate plans completed under the Energy Union Governance Regulation. ${ }^{80}$ These plans should include information on the measures ensuring that consumers participate in the energy system and benefit from self-generation and new technologies. ${ }^{81}$

The substantive rules for decentralization contained in the CEP oblige Member States to ensure that all consumers are entitled to become renewables self-consumers. ${ }^{82}$ Member States are also obliged to ensure that final (household) customers are entitled to participate in renewable energy communities while maintaining their rights or obligations as final customers. ${ }^{83}$ Furthermore, they must ensure that final customers are entitled to act as active customers without being subject to disproportionate or discriminatory technical and administrative requirements, procedures and charges, or to network charges that are not cost-reflective. ${ }^{84}$ Member States must provide a facilitative legal framework for citizen energy communities. ${ }^{85}$

The CEP also includes safeguards against inequality. In particular, it addresses the new risks that the energy consumers and their communities take in becoming more active participants in the energy markets. ${ }^{86}$ While

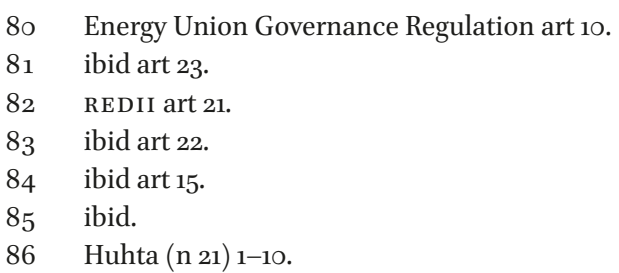


the previous EU legal framework provided some minimum consumer protection requirements, the provisions of the CEP are much more advanced. ${ }^{87}$ Vulnerable consumers lacking liquidity or otherwise opting out are protected from the turbulence of the transitioning sector. ${ }^{88}$ Chapter III of the Electricity Directive is entirely dedicated to energy poverty, consumer protection and empowerment. ${ }^{89}$ The chapter includes detailed provisions on basic contractual rights, ${ }^{90}$ on the rights to have a dynamic price contract, ${ }^{91}$ the right to switch suppliers ${ }^{92}$ and the freedom to enter into an aggregation contract. ${ }^{93}$ One of the CEP's main points of emphasis has been to guarantee 'a fair deal for consumers' by increasing consumer protection and rules on energy poverty, and there are several new provisions to this end. ${ }^{94}$ However, the CEP does not include a knowledge-sharing and capacity building programme for prosumers, which would offer knowledge and best practices to guide their behaviour. In this sense, it relies on a classical 'rational agent' model..$^{95}$ Although this can be remedied at lower levels of governance, a shared capacity building programme for prosumers would likely facilitate a quicker and more equitable transition to renewables.

Furthermore, achieving energy democracy in a market-based system depends on whether prosumers have equal opportunities in the system. At least two scenarios may work against this. First, if the price of electricity is low, prosumers may not have sufficient economic incentives to invest in smallscale generation. Second, market systems often provide equal opportunities to participate in power generation only for those that have the financial capacity to do so. If affluent households and communities shift to more self-sustaining systems, this may drive up electricity prices in the centralized grid for those that cannot move to decentralized generation. This would mean energy democracy for some, but not for all. If energy democracy is to be sought after in an equitable manner, the legal framework should include instruments to monitor the regional and household variability of decentralization and provide incentives for marginalized communities and households to contribute to

\footnotetext{
$87 \quad$ Lavrijssen (n 3) 172-187, 175.

88 Electricity Directive arts 28 and 29.

$89 \quad$ Lavrijssen (n 3) 172-187, 175 .

90 Electricity Directive art 10.

91 ibid art 11.

92 ibid art 12.

93 ibid art 13.

94 ibid recitals $30-37$ and $58-6$ o and arts $27-29$.

95 See e.g. Margaret Levi and others 'Introduction. The Limits of Rationality' in K S Cook and Margaret Levi (eds) The Limits of Rationality (University of Chicago Press 1990) 1-16.
} 
the democratization of electricity systems. As discussed further in section 3.4 below, this type of monitoring is needed for adaptive legal governance.

The second unwanted market dynamic is the uncertainty and risk related to energy security. To address the types of security risk that may emerge as a result of increasing intermittency in the electricity markets, the CEP includes an entirely new Regulation on Risk-Preparedness in the electricity sector. ${ }^{96}$ The Regulation lays down rules for cooperation between Member States with a view to preventing, preparing for and managing electricity crises. In essence, it creates three types of institutional safeguards against unpredictable developments. First, it includes an institutional structure and a methodology for predicting and thereby preventing security of supply crises that arise from the changes that take place in the electricity sector. ${ }^{97}$ Second, it includes institutional and methodological structures to manage electricity crises that occur despite the preventive measures. ${ }^{98}$ Finally, the Regulation includes an ex post evaluation method to assess whether the measures taken in the crisis were adequate. ${ }^{99}$

The framework for managing and preparing for shocks and other unpredictable dynamics in the electricity sector fares well in the evaluation. In line with complexity theory, the regulation promotes collaboration between Member States with interconnected electricity systems and establishes mechanisms to prepare for shocks. Furthermore, operations under unexpected system states are considered. Moreover, the framework contains an ex post evaluation of preparation and management measures facilitating institutional learning for future shocks. In complexity informed environmental law scholarship this is commonly called passive adaptive management (i.e. learning from past system dynamics). ${ }^{100}$

\subsection{Adaptation of the Law}

The final criterion for assessing law for complex systems focuses on law's ability to self-evaluate and adjust on the basis of changes taking place in the real world. This means that in order to increase adaptive capacity, the legal frameworks should include monitoring and evaluation tools that can trigger

$96 \quad$ The Risk-Preparedness Regulation.

97 ibid arts $3^{-13}$.

98 ibid arts 14 and 15 .

99 ibid art 17.

100 See Byron K Williams, 'Passive and active adaptive management: Approaches and an example' (2011) 92 Journal of Environmental Management 1371-1378. 
action if it seems that the objectives of the legal framework are at risk of being undermined.

To cope with this type of change and uncertainty, the CEP contains mechanisms for revising and updating existing legislation. The Energy Union Governance Regulation includes monitoring and reporting obligations for the Member States that require them to report to the EU on their progress on issues, including decentralized systems. ${ }^{101}$ It also includes a specific provision on how the legislation can be reviewed to address changes in the real world or inadequacies in the legislation in terms of addressing its goals. ${ }^{102}$ It even calls for an energy governance mechanism that is democratic in character. ${ }^{103}$ In addition, it is clear that in future the EU Green Deal, for instance, will increase legislative action in the energy sector, which gives further options to revise and improve the legislation to cope with change and uncertainty. ${ }^{104}$ With these key elements in place, the CEP can be adapted if current legal measures prove unsuccessful in regulating the electricity system in such a way as to further energy democracy and security.

\section{4}

\section{Conclusions}

This chapter has sought to analyse and offer insight into some of the key legal considerations in decentralized electricity systems, using the EU as an example. First, the chapter used complexity theory to explain the dynamics of decentralized electricity systems. Second, it used legal scholarship informed by complexity theory to evaluate the functionality of the CEP. The latter analysis focused on assessing whether the legal structures and regulatory choices made in the CEP are equipped to manage the complexity of decentralized electricity systems in such a way as to facilitate energy democracy and protect energy security.

In order to understand whether and how decentralized electricity systems can deliver sustainable energy democracy these systems must be taken for what they are: complex systems. As shown in section 2, complexity refers not only to a complicated set of energy sources, energy usages and processes,

\footnotetext{
101 Energy Union Governance Regulation annex I.

102 ibid art 45.

103 ibid recital 16.

104 Communication from the Commission to the European Parliament, the European Council, the Council, the European Economic and Social Committee and the Committee of the Regions, The European Green Deal, сом/2019/640 final.
} 
agents and institutions which are all inherently interconnected and intertwined, but to a set of key properties that feature in decentralized electricity systems. Decentralized electricity systems produce emergent patterns that are not attributable to any single system agent or component. They are also nonlinear, meaning that changes in system conditions can have disproportionate outcomes. Decentralized electricity systems are adaptive, meaning that public and private agents respond to and change behaviour in the face of change. Furthermore, they are inherently indeterminate and unpredictable. They are also self-organizing, meaning that no public or private agent or institution can hope to exercise comprehensive control over the system. Finally, decentralized electricity systems are nested in, and coevolve with, other systems such as the economy and law. Consequently, regulatory interventions need to be designed with care and attention to take account of these systemic traits.

Section 3 identified the main criteria from complexity informed legal scholarship to evaluate laws that govern complex systems. These are: (1) facilitating market and/or other local choices; (2) checking unwanted market dynamics with legal-institutional, procedural and substantive rules; (3) facilitating adaptation of the law itself.

Application of the complexity criteria to analysis of the CEP in section 3 showed it to be on a solid footing: the constitutional backbone for EU energy law and the CEP is characterized by legally binding goals and a bottom-up, market-based strategy in which prosumers are empowered to assume the dual role of producer and consumer. However, some potential challenges loom on the horizon. The package aims at making the energy system carbon neutral while protecting consumers and increasing their influence in the system. Considering the complex dynamics of decentralized electricity systems discussed in section 2, the disruptive goal of transforming the current carbondependant and undemocratic system is likely to have unintended positive and negative impacts on other important EU goals, such as energy security. Consequently, a decentralized regulatory strategy puts significant pressure on the legal safeguards for unwanted market dynamics.

From the complexity theory perspective, the main role for the legal instruments that comprise the CEP is to provide societal direction and check for unwanted market dynamics. The latter can be divided into two main categories: protecting vulnerable households from market forces and preparing the electricity system for shocks to energy security. Regarding the first of these, the legal framework was found to lack sufficient safeguards and capacity building for financially impoverished households in a decentralized system. Based on the unequal financial and knowledge capacities of households across the $\mathrm{EU}$, the legal framework may usher in equity challenges despite the goal of 
ensuring clean energy for all, not only for some. As to the second, the CEP does contain sufficient tools for managing shocks to energy security.

Finally, adaptation of the law itself was found to include key mechanisms for adjusting the legal requirements as new and sometimes unexpected system dynamics emerge. To this end, the CEP contains mechanisms for revising and updating existing legislation as well as tools for predicting, managing and learning from shocks as they unfold. Considering all three sets of criteria discussed in this chapter, it seems that the new EU legal framework for decentralized electricity fulfils most complexity-informed legal criteria well and offers a global benchmark for a democratic, climate-smart and energy secure legal framework. 